\title{
The Impact Of Transformational And Transactional Leadership Styles On Employee's Satisfaction And Performance: An Empirical Test In A Multicultural Environment
}

Cedwyn Fernandes, (E-mail: CedwynFernandes@uowdubai.ac.ae), University of Wollongong in Dubai, UAE Raed Awamleh, (E-mail:ReadAwamleh@uowdubai.ac.ae), University of Wollongong in Dubai, UAE

\begin{abstract}
This study tests the transformational leadership theory among managers at functional levels in United Arab Emirates (UAE) international companies. The UAE business sector was chosen due to its significance in the regional economy and its sizable contributions as the UAE continues to lead its neighboring countries in business development and technological advancements. More specifically, the UAE economy depends very heavily on expatriate workers and professionals, which creates a rich yet challenging environment for leadership models. The paper examines the effects of both transformational and transactional leadership styles of managers/supervisors on employees' satisfaction and self-perceived performance. Self-esteem and leadership disposition (Romance of Leadership) of employees are hypothesized to act as moderators. The impact of cultural origin, gender, age, and job experience are also examined. Data was collected from employees working in international companies operating in the UAE. Results revealed a strong effect for transformational leadership on satisfaction. Importantly, results do challenge the view that both leadership styles are necessary conditions for leadership to be operationalized. Cultural and demographic factors showed strong impact on the dependent variables as did RLS and selfesteem. All findings are discussed and future research directions outlined.
\end{abstract}

\section{Introduction}

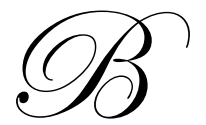

oth transformational and transactional leadership styles and their respective and combined effects on business organizations have been at the center of leadership research (e.g., Awamleh \& Gardner, 1999; Bass, 1985; Conger \& Kanungo, 1987; House, 1977). Commonly, a number of vital organizational outcomes are linked to these leadership styles including satisfaction, organizational performance, group performance, and commitment (e.g., Kirkpatrick and Locke, 1996). Furthermore, the impact of transformational leadership styles on followers' effectiveness and motivation has also been documented (e.g., Bass \& Avolio, 1990; 1994). In spite of this, however, limited research has been conducted examining effects of managerial leadership styles -from transformational and transactional perspectives- in true multicultural environment, which is a gap that this paper attempts to fill. The researchers designed a study to assess the effects of transformational leadership styles as apposed to transactional on employees' self-perceived performance and job satisfaction in a the UAE business environment where eighty percent of total work force consist of expatriates coming from widely diversified backgrounds (more than 120 nationalities). Additionally, two possible moderating variables are 
considered. These are self-esteem (Rosenberg, 1979), and Romance of Leadership (Meindl, 1995). Other important cultural and demographic factors were also addressed.

\section{Literature Review}

Transformational and Transactional Leadership

Transformational leadership originated from charismatic leadership. The word charisma comes from the Greek word that means gift of grace. Charismatic authority is derived from faith in the leader's exemplary character (Conger \& Kanungo, 1987). Specifically, House (1977) maintains that the personal characteristics of the charismatic leader include a high degree of self-confidence, strong moral convictions, and a tendency to influence others as well as engaging in impression management behaviors to boost trust and confidence in the leader. Furthermore, the articulation of a mission, setting challenging goals, and arousing motives are also important.

While advancing Burn's (1978) model, Bass (1985) proposed a new theory of transformational leadership and outlined its components. To understand transformational leadership, we must differentiate it from transactional leadership. Transactional leadership is based on the exchange process where the leader administers rewards and sanctions. The leader and follower agree, explicitly or implicitly, that desired follower behaviors will be rewarded, while undesirable behaviors will draw out punishment. Potential rewards include an increase in salary, promotions, and more benefits. Conversely, penalties may include pay cuts, demotions, and terminations. Based on this, one could argue that transactional leadership behaviors do not even qualify for a "true" leadership label (Bryman, 1992). Since it is based on exchange, transactional leadership does not seek to motivate followers beyond the level that is required to avoid punishment or gain extrinsic rewards. Accordingly, total reliance on this leadership style may cause performance and satisfaction to suffer (Bass, 1985; Bryman, 1992; Burns; 1978; Peters \& Austin, 1985). Transformational leadership, however, engages followers by appealing to their upper level needs and ideals that yield higher levels of follower satisfaction and performance (Bass, 1985; Bryman; 1992). Unlike Burns (1978), Bass (1985) insists that, to be effective, leaders need to demonstrate features of both transactional and transformational leadership. Empirical evidence tends to support the view that leaders will maximize their effectiveness when they exhibit both transformational and transactional behaviors (e.g., Avolio, Waldman, \& Einstein, 1988; Waldman, Bass, \& Yammarino, 1989).

As modeled by Bass, transactional leadership is comprised of two fundamental dimensions: contingent reward and management-by-exception, while transformational leadership is comprised of four central components: charisma, inspiration, individualized consideration, and intellectual stimulation. Contingent reward takes place when the leader and follower have a mutual understanding of the rewards or sanctions for performance or nonperformance. The emphasis is on completing tasks that have been agreed upon based on previous expectations. In Management-by-Exception, however, the leader takes action only when major deviations from plans are evident.

Charisma is the key component of transformational leadership, it generates profound emotional connection between the leader and follower and it creates excitement about the mission (Bass, 1985). Charisma is opertionalized through vision where the charismatic leader earns the respect and trust of followers, which leads to the acceptance of challenging goals (Bass \& Avolio, 1990). The second transformational component is inspiration where leaders communicate their vision with optimism and enthusiasm. They also use symbols to heighten awareness of desired goals (Bass \& Avolio, 1990). Another major component of transformational leadership is individualized consideration where the leader gives personal attention to followers by treating them "differently but equitably" (Bass \& Avolio, 1990). In exhibiting individualized consideration, the leader first identifies the individual needs and abilities of followers and then mentors and coaches them, and also uses delegation. Finally, intellectual stimulation. Here the leader helps followers to think on their own and analyze problems from their personal perspectives, encourages creativity, innovation, and challenge conventional wisdom (Bass \& Avolio, 1990). 
Bass (1985) developed the Multifactor Leadership Questionnaire (MLQ) to measure the components of transformational and transactional leadership. Since its development, the MLQ has received extensive evidence of its reliability and validity, and is commonly used in leadership research (Bryman, 1992).

\section{Self-Esteem}

Self-esteem can be defined as a set of attitudes and beliefs that a person brings with him or herself when facing the world (Wells \& Marwell, 1976). Self-esteem has been used to explore such areas as conformity, responses to threats, social participation, competitive behavior, and causal attributions. Some of the related terms include selflove, self-confidence, self-respect, and self-worth. High self-esteem is associated with risk taking, job satisfaction, and low inclination to please others (Brockner, 1988).

\section{Romance of Leadership}

Romance of leadership as a construct refers to the generalized beliefs that individuals have regarding the significance of leadership to organizations which may influence how they see their leaders (Meindl, Ehrlich, and Dukerich; 1985). These beliefs enhance followers' perceptions of charismatic/transformational qualities. Meindl and Ehrlich (1988) have developed the Romance of Leadership Scale (RLS). However, up to this point, only inconclusive empirical evidence is available regarding this concept (e.g., Al-Dmour \& Awamleh; 2002, Awamleh \& Gardner; 1999, Meindl; 1988).

\section{Hypotheses}

Based on review of literature, the following hypotheses were advanced:

H1: There is a significant relationship between transactional leadership style of UAE international companies mangerslsupervisors and employees' a) job satisfaction, and b) self-perceived performance.

$\mathrm{H} 2$ : There is a significant relationship between transformational leadership style of UAE international companies mangerslsupervisors and employee's a) job satisfaction, and b) self-perceived performance.

H3: There is a significant relationship between individual differences of UAE international companies employees' (Self-esteem and RLS) and their a) job satisfaction, and b) self-perceived performance.

H4: The relationship of leadership styles of UAE international companies mangerslsupervisors and a) job satisfaction, and b) self-perceived performance, of employees is moderated by individual differences (Self-esteem and RLS).

In addition to the hypotheses, and in areas where literature review and previous research is lacking, the authors intended to explore a number of research questions on the multicultural aspects of the study. These were:

Q1: What is the impact of interaction of various cultural backgrounds of subjects?

Q2: What is the impact of on the job experience?

Q3: What is the impact of gender?

Q.4: What is the impact of age? 


\section{Method}

Population, Sample, and Subjects

Population of this study consisted of all internationally owned and operated companies in the UAE across various industries and sectors. Thousands of international companies operate in the UAE inside and outside the free zones, a large number of them use the UAE as their base in the region. They are attracted to the UAE because of its advanced infrastructure, modern investment laws, and its wide pool of expatriate professionals who are young and tend to be highly skilled. The majority of these workers come from the Indian subcontinent (51.3\%), Arab region (37.4\%), Eastern and Western Europe, North America, Australia and New Zealand (2.2\%). A random sample of these companies was taken out of published business directories, a total of 295 were contacted and 65 of them agreed to participate. A total of 315 questionnaires were distributed by hand. The number of questionnaires for each company was determined by the size of its workforce. Subjects were employees in non-managerial positions working full time. One hundred and eighty questionnaires were returned (picked up by hand from companies) which is 57 percent, out of these 141 were used and the remaining excluded for missing data or because they were filled out by other than the indented subject resulting in 45 percent accurate reply rate $(55 \%$ of the respondents were male; $90 \%$ of respondents hold Bachelor degree or higher; $29 \%$ had more than 5 years experience, and India, Lebanon, and Jordan were the dominant countries). Data collection took two months.

\section{Measures}

The Multifactor Leadership Questionnaire (MLQ-5x/Short Form) (Bass \& Avolio, 1995) was employed to measure transformational and transactional leadership styles. For the purpose of this study, four subscales were loaded together and used as a measure for transformational leadership (Charisma, e.g., "my manager instills pride in being associated with him", Inspiration, e.g., "my manager talks enthusiastically about what needs to be accomplished", Individualized Consideration, e.g., "my managers helps me develop my strengths", and Intellectual Stimulation, e.g., "my manager seeks differing perspectives when solving problems"), a total of 21 items. Transactional leadership style was measured by two subscales (Contingent Rewards, e.g., "my manager provides me with assistance in exchange for my efforts", and Management-by-Exception, e.g., "my manager waits to take action until things go wrong"), a total of 7 items.

To measure self-esteem, Rosenberg's (1979) 10-item scale was adopted. Example items of this scale include, "I feel I have a number of good qualities", "I am able to do things as well as most other people", and "At times, I think I am no good at all". As for the last individual difference, Romance of Leadership, the RLS scale developed by Meindl and Ehrlich (1988) was adopted. The original Scale contained 32 items. However, several versions of RLS have appeared since its development. The current study used Form C (RLS-C), which has 11 items. Examples of items include, "when it comes right down to it, the quality of leadership is the single most important influence on the functioning of an organization", "the process by which leaders are selected is extremely important", and "a company is only as good as its leaders".

The authors adopted two instruments to measure the dependent variables, these were developed and validated by Al-Dmour and Awamleh (2002). Job satisfaction was assessed by a 14-item scale covering areas normally tapped in organizational behavior research. Examples of items include, "In general, I am satisfied with work", "I find that my opinions are respected at work", and "My job provides me with adequate financial rewards". As for the self-assessed performance scale, it is comprised of 5 items such as "I consider my performance better than the average sales person in my company", and "I always reach my sales targets".

The entire set of these scales was included in one questionnaire. They all used a unified 5-point Likert scale. The questionnaire included a total of 75 items. 


\section{Results}

\section{Scale Reliabilities}

According to Nunnally (1978) scale reliabilities (Cronbach Alphas) that are less than 0.6 are considered poor, those in the 0.7 range are acceptable, while those above 0.8 are good. Results showed that the transformational leadership style scale reliability estimate is 0.92 , and that of transactional is 0.79 . Job satisfaction scale showed a reliability of 0.84 , while performance scored 0.76 . Reliabilities for self-esteem, and RLS were 0.81 , 0.74 respectively.

\section{Correlations}

Intercorelations among all variables used in this study are summarized in Table 1. It is noted that the dependent variables show extremely low correlatetion $(r=0.15, p<0.066)$. It is also worth mentioning that transformational and transactional styles of leadership are highly correlated $(r=0.80, p<0.001)$, which would be expected given the fact that they are supposed to act as paired and not as contradictory factors.

Table 1. Intercorrelations of Self-Esteem, Self-Perceived Performance, RLS, Job Satisfaction, Transactional, and Transformational Leadership.

\begin{tabular}{|c|c|c|c|c|c|}
\hline & 1 & 2 & 3 & 4 & 5 \\
\hline \multicolumn{6}{|l|}{ RLS } \\
\hline Self-Esteem & $0.36 * *$ & & & & \\
\hline Satisfaction & 0.16 & $0.28 * *$ & & & \\
\hline Performance & $0.44 * *$ & $0.47 * *$ & 0.15 & & \\
\hline Transformational & $0.22 * *$ & $0.22 * *$ & $0.40 * *$ & $0.25 * *$ & \\
\hline Transactional & 0.16 & 0.14 & $0.39 * *$ & $0.17 *$ & $0.80^{* *}$ \\
\hline
\end{tabular}

**correlation is sig. at $\mathrm{p}<0.01$

*correlation is sig. at $\mathrm{p}<0.05$

\section{Hypotheses Testing: Multiple Regression and Partial Correlation Results}

Two multiple regression models were run in order to test the first three hypotheses. Table 2 shows results of the multiple regression test with self-perceived job performance $(m=2.03 ; S D=0.63)$ acting as the dependent variable and entering transformational leadership $(m=2.55$; $S D=0.75)$, transactional leadership $(m=2.54 ; S D=0.78)$, selfesteem $(m=2.02 ; S D=0.63)$, and RLS $(m=2.21 ; S D=0.53)$ as factors. The overall model is significant at $p<$ 0.001 . Multiple regression revealed significant impact of RLS $(p<0.001)$, and self-esteem $(p<0.001)$. Conversely, transformational leadership and transactional leadership failed to show any significant relationship with job performance. 
Table 2. Multiple Regression. Self-Perceived Performance is dependent variable.

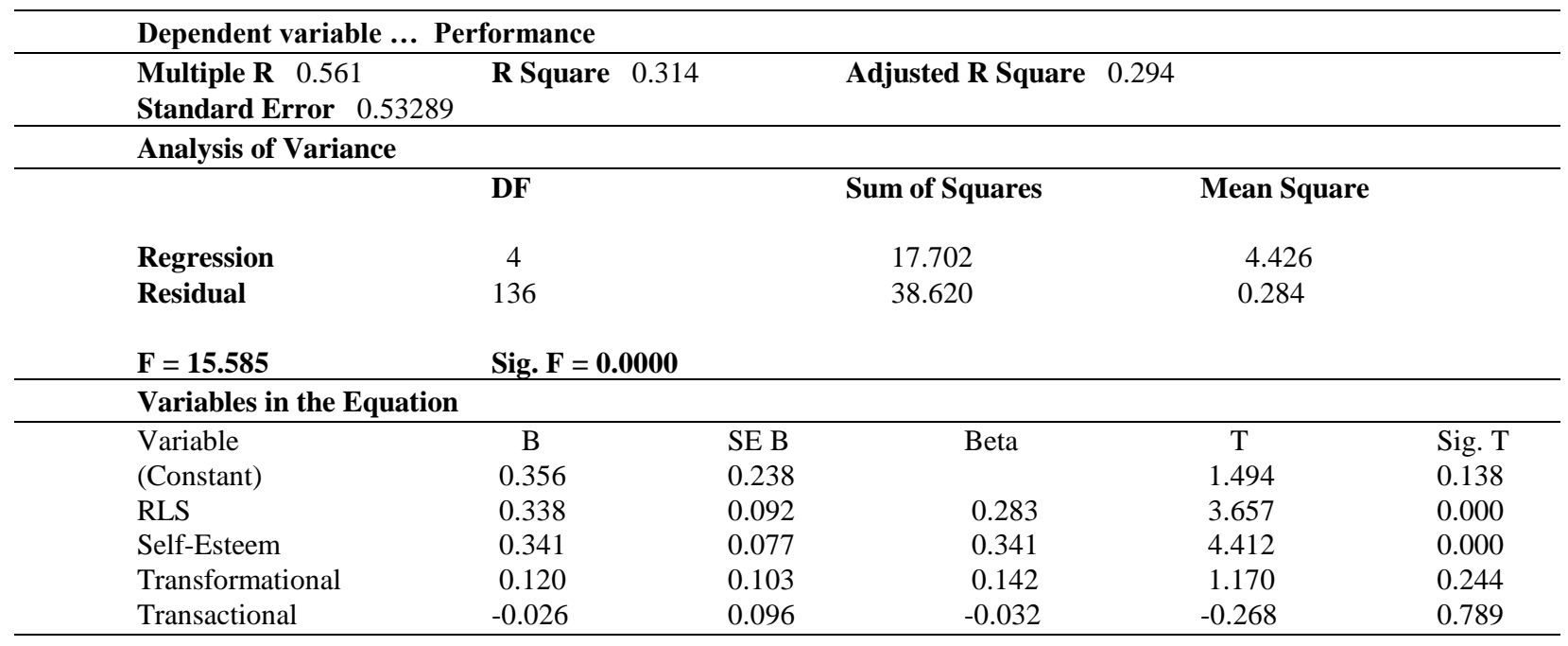

Results of the second multiple regression are shown in Table 3. Here, the test was conducted with job satisfaction $(m=2.52 ; S D=0.75)$ as the dependent variable while self-esteem, RLS, transformational leadership, and transactional leadership all entered as factors. Like the first test, the overall model is significant at $p<0.001$. Transformational leadership style showed significance at the $p<0.05$ level, as well as self-esteem. However, RLS, and transactional leadership showed no relationship.

To test the remaining hypothesis, a partial correlation is run controlling for self-esteem and RLS (Table 4). Compared to inter-correlations presented in Table 1, it is witnessed that correlations, albeit still significant, are greatly reduced in all cases with no exception. Two correlations worth noting here. The first is between transformational leadership style and performance $(r=.13$, non-significant $)$ and the other is between transactional leadership style and performance ( $r=.09$, non-significant), which is very consistent with findings of the multiple regressions presented earlier where performance was not at all related to either leadership styles.

Table 3. Multiple Regression. Job Satisfaction is dependent variable.

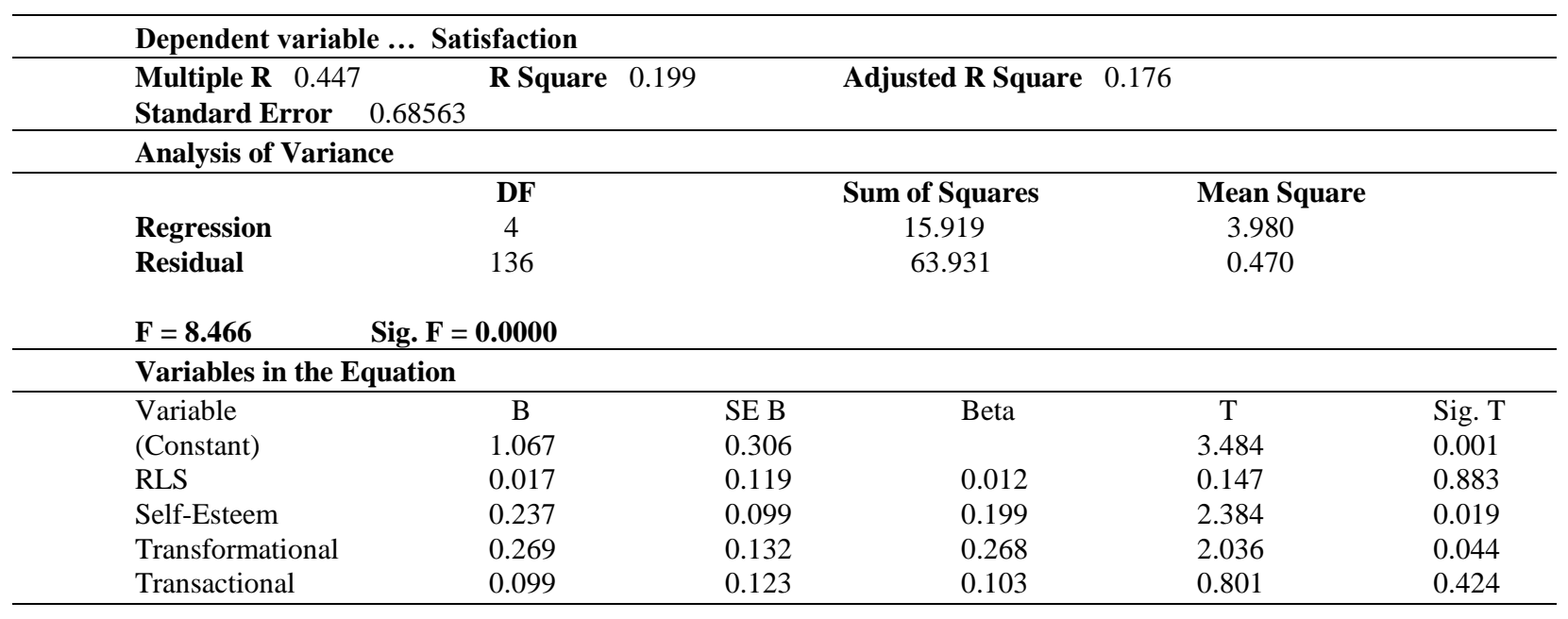


Table 4. Partial Correlations controlling for Self-Esteem, RLS, and Self-Efficacy.

\begin{tabular}{|c|c|c|c|c|c|}
\hline & 1 & & 2 & & 3 \\
\hline Satisfaction & & & & & \\
\hline Performance & 0.08 & & & & \\
\hline Transformational & & $0.35 * *$ & & 0.13 & \\
\hline Transactional & $0.32 * *$ & & 0.09 & & $0.79 * *$ \\
\hline
\end{tabular}

\section{Research Questions: Multiple Regressions}

In attempting to answer the research questions (about which exists no conclusive or substantial body of knowledge in the situation that is under consideration), a number of multiple regressions were run. Initially, two sets of data were extracted for two age groups (less than or equal to 30 and over 30), for experience on the job (less than or equal to 5 years or more than 5 years), and male or female. The issue of cultural background, however, was not so straightforward. Data revealed that there were only two groups with substantial numbers in the sample to warrant statistical analysis, these were Arabs (including UAE nationals) and Indian subcontinent nationals. Others in the sample were from wide and diversified backgrounds that did not constitute a homogenous cultural background, or any clusters of it, and therefore were excluded from this part of the analysis (Those small numbers came from countries such as Australia, Sweden, Turkey, Poland, Nigeria, and China).

Multiple regressions were run for all four demographic and cultural variables mentioned above with satisfaction and self-perceived performance as dependent variables and transformational, transactional, self esteem, RLS as independent variables in each model. A number of the tested relationships turned out to be significant. In the interest of parsimony though, not all details of regression analysis will be reported, instead a summary table is presented below showing only significant findings (Table 5).

Table 5. Cultural and Demographic Variables

\begin{tabular}{|c|c|c|}
\hline Category & Satisfaction* & Performance* \\
\hline \multicolumn{3}{|l|}{ Cultural Background } \\
\hline \multirow[t]{3}{*}{ Indian Sub. Cont. } & Self-Esteem 0.003 & RLS 0.013 \\
\hline & & Self-Esteem 0.000 \\
\hline & & Transformational 0.006 \\
\hline \multicolumn{3}{|l|}{ Arabs } \\
\hline \multicolumn{3}{|l|}{ Gender } \\
\hline \multirow[t]{2}{*}{ Male } & & RLS 0.001 \\
\hline & & Self-Esteem 0.002 \\
\hline \multirow[t]{2}{*}{ Female } & Self-Esteem 0.028 & RLS 0.047 \\
\hline & Transformational 0.044 & Self-Esteem 0.042 \\
\hline \multicolumn{3}{|l|}{ Job Experience } \\
\hline \multirow{2}{*}{ Less than or equal to 5 years } & Transformational 0.001 & Self-Esteem 0.000 \\
\hline & & RLS 0.002 \\
\hline More than 5 years & Self-Esteem 0.008 & \\
\hline \multicolumn{3}{|l|}{ Age } \\
\hline Less than or equal to 30 years & Transformational 0.036 & Self-Esteem 0.007 \\
\hline More than 30 & Self-Esteem 0.002 & RLS 0.001 \\
\hline * All values show significance of $\mathrm{T}$ & & \\
\hline
\end{tabular}




\section{Discussion}

Results of the statistical analyses provide partial support for some hypotheses and full or no support for others. Explicitly, results indicate that Hypothesis 1 ( $a$ and $b$ ) is not supported where transactional style of leadership is not significantly related to self-perceived performance or to satisfaction. Hypothesis 2a, however, had a clear support where transformational leadership style is directly related to satisfaction. In sum, both leadership styles failed to show any relationship with perceived job performance.

The third hypothesis received mixed support. Multiple regression revealed that both RLS and self-esteem are significantly related to self-perceived performance, whereas self-esteem alone is significantly related to job satisfaction. As for the fourth hypothesis, partial correlation controlling for the two individual differences revealed a weaker correlation between dependent and independent variables in all cases. This indicates that RLS and selfesteem taken together positively and considerably mediate those relationships.

\section{Effects of Transformational Leadership}

Findings of this study confirm that transformational leadership style of mangers will boost employees' job satisfaction. When mangers operationalize charisma and utilize inspiration, individualized consideration, and intellectual stimulation they elicit positive reactions from employees. Seemingly, such transformational qualities do indeed stimulate higher level needs of followers and result in higher feelings of satisfaction. This finding is supported by the rationale of other leadership researchers (e.g., Bass \& Avolio, 1990). The attention that managers give to employees will be reflected in their general positive attitude toward work and work conditions, which in turn increases job satisfaction. However, transformational leadership came out as unrelated to employees' self-perceived performance, unlike what we predicted earlier. This result will be discussed further in the combined effects section.

\section{Effects of Transactional Leadership}

Surprisingly, and dissimilar to previous findings, transactional leadership style is not related at all to selfperceived performance or to job satisfaction. Does this illustrate that followers in international UAE companies do not respond to contingent rewards or management-by-exception when it comes to satisfaction and self-perceived performance? Probably not. It has been observed that businesses in the UAE have not developed systems of empowerment or delegation, instead employees are governed by strict employment contracts (the vast majority of these contracts are closed ended with expiration dates clearly defined) and the market is believed to exhibit relatively high employee turnover levels. However, management is seen to be stable and top managers maintain relatively long tenures. No tenure system exists for employees. The potential for promotion and advancements for expatriate workers is limited and therefore performance targets and expectations are spelled out through strong corporate cultures and salient other organizational characteristics making patent performance-reward linkages without the need for a manager to articulate them. This employment condition in the expatriate transient employment market could have neutralized the effect of transactional leadership. It must be noted however, that the above claims are mostly based on popular beliefs regarding the employment market as there is a lack of reliable and objective scientific studies to substantiate market features and conditions.

\section{Combined Effects of Transformational and Transactional Leadership Styles}

Based on theory and earlier empirical studies, we predicted both independent variables to be significantly related to job satisfaction and self-perceived performance since we view both leadership styles to be complementary as was shown in a recent study (Al-Dmour and Awamleh; 2002). However, results clearly show that only transformational style is positively and significantly related to satisfaction. Indeed, this is a major result that requires explanation. Our interpretation of this result rests upon the fact that the operations of UAE international companies are specialized and standardized to a high degree, especially at the processing level, which leaves no room for high variations in performance. Individual performance, is for the most part, determined by the flow of work, more than the input of managers especially on daily or weekly basis. Of course, as the performance in this study is self- 
assessed, it reflects only what employees perceive as the role of their manger. On the other hand, satisfaction is significantly influenced by transformational style. Evidently, while employees felt that their performance is less influenced by the manger, they attributed part of their satisfaction to him/her. In such programmed environments, satisfaction becomes a result of appealing to higher level needs which helps to overcome the routine and the frustration of limited career planning and restricted participation. Importantly, the results show that in some environments, both leadership styles are not necessarily complementary, indeed as in this case one can have an impact without the other. Although there exists no evidence here to support the view that both styles are necessary conditions for leadership or that they both act as components of same construct, there is also no evidence to suggest that they are competing or opposite of each other.

\section{Effects of RLS and Self-esteem}

Mixed support was given to the romance of leadership construct in the current study. Results showed it to be a positive moderator of performance, but not satisfaction. The more positive a disposition toward leadership that an employee has, the more likely he or she will have high perceived performance, but not satisfaction. In particular, subjects who believe in the importance of leadership seem to think that it can facilitate their performance which supports the general premise of the construct. Yet, satisfaction in this case seems to be affected by other and more diversified factors. And as expected self-esteem was shown to be significantly related to both performance and satisfaction. Specifically, the higher self-esteem an employee has, the higher his self-assessed performance and satisfaction will be in the presence of both transformational and transactional leadership styles.

\section{Effects of Cultural Origin, Gender, Job Experience, and Age}

As this is a highly multicultural and diversified group, further data analyses revealed interesting findings where sometimes the subgroups reacted differently from the overall group to a certain stimuli. Specifically, the Indian subgroup responded positively to transformational leadership when it came to performance, unlike the overall group and the Arab subgroup. This can be partly explained by Hofstede's (2001) finding that Indian Subcontinent individuals do not separate their professional life from their personal life. This may mean that they expect leaders at work to be emotionally engaging in the way they respond to their needs which is directly related to performance.

As for the Arab group, it is surprising to see that they have shown no significant response to any of the factors. No available cultural model explains this finding which strongly warrants further study before making conclusions.

On the gender side, the main finding is that unlike the overall group, men did not respond as positively as women to transformational leadership with regards to satisfaction. This result is consistent with the belief that women are more process oriented and care more about how goals are achieved not only that they are achieved. Of course, the process is a central theme in transformational leadership as opposed to transactional style which focuses on end results.

Interestingly, age and job experience showed high correlation in the way they related to study factors. Unlike the overall group, those who have five or less years of job experience and those who are thirty years old or less significantly related to transformational leadership. It seems that older employees and the more experienced ones in the job become desensitized to the transformational leadership style in the environment of study as it does not bring in major changes in the medium and long terms. More specifically, and unlike the others, they develop cynicism or perhaps indifference. In light of the unsubstantiated results of some UAE business surveys which claim that the average length of stay in the country for expatriate workers is five years, this result makes sense. After a while, workers in this environment mentally and emotionally disengage and begin focusing on the next move. 


\section{Limitations and Future Research Directions}

Obviously, the interaction of leadership styles and followers' performance necessitates additional analyses. Moreover, further investigation of the UAE business environment is necessary. Was the situational variable responsible for lack of significance in the performance leadership relationship? Or are the reasons more general or more specific? This study either did not capture that relationship properly or the situational factors were strong enough to override. If so, what are these factors? Are they mainly the multicultural ones, or nature of the workforce demographics, or international companies practices? Once more, it must be mentioned that performance was measured using a self-assessment instrument. This a possible limitation as self assessed performance is commonly overrated (e.g., Bretz, Mikovich, \& Read; 1992). Furthermore, the nature of contact that employees have with their managers and the level of closeness were not assessed. Mainly, the cultural and demographic factors warrant deeper and wider investigation.

The above limitations provide us with some clues for future research directions. Areas that deserve attention include the relationship between leadership style and independently measured performance. Also worthy of scholarly attention is the assessment of effects that skills level, career aspirations, and realistic expectations have on perceptions of leadership. Moreover, the satisfaction relationship should be further explored. For example, how would task structure, position power, and group norms impact satisfaction.

\section{Conclusion}

Even though the majority of transformational/transactional leadership models presume that followers attribute leadership qualities based on face-to-face exchanges with the leader, the mass of studies in this area measure distant as opposed to close leadership relationship. This, we argue, weakens their results and invites criticism. For example, Meindl (1995) contends that attributions of leadership often emerge from social contagion processes, whereby influential followers "spread the word" to persons who lack direct contact with the leader. Yet, this study is different, leadership qualities were tapped at a functional level. More specifically, this study provides evidence of transformational and transactional effects in a real organizational setting where followers were assessing the leader the know well and interact with on daily base.

A crucial finding of this study is that transformational and transactional styles are not that complementary in some settings. It is shown in this study that followers do not expect or do not respond positively to the attributes of both leadership styles functioning at the same time. This contradicts other research findings and should be further explored. We suspect that the environment is a major factor and suggest that it be analyzed.

Interestingly, and contrary to a history of inconclusive evidence, leadership disposition among followers played a strong role in this study. Followers seem to react positively in terms of performance when a strong presence of leadership is maintained, they seem to expect it. This finding could have a cultural dimension though, as people in certain cultures come to accept such a conclusion as a natural condition. Still, we would predict that in situations like this one, where the leader-follower interaction is close and continuous, the impact of RLS will be minimized over a long period of time in favor of real experience with the leader. Self-esteem is confirmed again a major factor role in eliciting higher performance and satisfaction levels. Significantly, cultural and demographic factors which where explored by this study revealed important results and more analyses of them are required in this somewhat unique employment market.

Lastly, we wish to emphasize that since leadership has been shown to be a key factor for eliciting higher levels of individual satisfaction, we should focus on training and developing more managers to become leader. More specifically, cultural training for managers needs to be on the agenda of international companies in a more serious and systematic way. We would argue that international companies operating in the market under study stand to gain competitive advantage from digging deeper into the dynamics of their human assets and from designing training programs that address the practical needs. In addition to training, human resource practices and corporate strategies 
should be amended to cope with cultural and demographic emerging factors as the UAE continues to change and develop rapidly.

\section{References}

1. Al-Dmour, H, \& Awamleh, R. A. 2002. Effects of Transactional and Transformational Leadership Styles of Sales Managers on Job Satisfaction and Self-Perceived Performance of Sales People: A study of Jordanian Manufacturing Public Shareholding Companies. Dirasat: Administrative Sciences Series, 29(1): 247-261.

2. Awamleh, R. A., \& Gardner, W. L. 1999. Perceptions of Leader Charisma and Effectiveness: the Effects of Vision Content, Delivery, and Organizational Performance. Leadership Quarterly, 10(3), 345-373.

3. Avolio, B. J., Waldman, D. A., \& Einstein, W. O. 1988. Transformational Leadership in a Management Game Simulation. Group \& Organization Studies, 13(1): 59-80.

4. $\quad$ Bass, B. M. 1985. Leadership and Performance Beyond Expectations. New York: Free Press.

5. Bass, B. M. \& Avolio, B. J. 1990. The Implications of Transactional and Transformational leadership for Individual, Team, and Organizational Development. Research in Organizational Change and Development, 4: 231-272.

6. Bass, B. M. \& Avolio, B. J. 1993. Transformational leadership: A Response to Critiques. In M. M. Chemers \& R. Ayman, Leadership Theory and Research: Perspectives and directions. San Diego: Academic Press.

7. Bretz Jr, R. D., Milkovich, G. T., \& Read, W. 1992. The Current State of Performance Appraisal Research and Practice: Concepts, Directions, and Implications. Journal of Management, June 323-24.

8. Brockner, J. 1988. Self-Esteem at Work. Lexington, MA: Lexington Books.

9. Bryman, A. 1992. Charisma and Leadership in Organizations. London: Sage.

10. Burns, J. M., 1978. Leadership. New York: Harper and Row.

11. Conger, J. A. \& Kanungo, R. N. \& Associates (Eds.) 1987. Charismatic leadership: the Elusive Factor in Organizational Effectiveness. San Francisco: Jossey-Bass.

12. Conger, J. A. \& Kanungo, R. N. 1994. Charismatic leadership in Organizations: Perceived Behavioral Attributes and their Measurement. Journal of Organizational Behavior, 15: 439-452.

13. Ehrlich, S. B., Meindl, J. R. \& Viellieu, B. 1990. The Charismatic Appeal of a Transformational Leader: An Empirical Case Study of Small, High Technology Contractor. Leadership Quarterly, 1(4): 229-248.

14. Hofstede, G. 2001. Culture's consequences: Comparing values, behaviors, institutions, and organizations across nations. London: Sage Publications.

15. Holladay, S. J., \& Coombs, W. T. 1994. Speaking of Visions and Visions being spoken: An Exploration of the Effects of Content and Delivery on Perceptions of Leader Charisma. Management Communication Quarterly, 8(2): 165-189.

16. House, R. J. 1977. A 1976 Theory of Charismatic Leadership. In J. G. Hunt \& L. L. Larson (Eds.), Leadership: The cutting edge, 189-204. Carbondale, IL: Southern Illinois University.

17. Howell, J. M., \& Frost, P. J. 1989. A laboratory Study of Charismatic Leadership. Organizational Behavior and Human Decision Processes, 43: 243-269.

18. Kanungo, R. N., \& Mendoca, M. 1996. Ethical Dimensions of Leadership. Thousand Oaks, CA: Sage.

19. Kirkpatrick, S. A \& Locke, E. A. 1996. Direct and indirect effects of three core charismatic leadership components on performance and attitudes. Journal of Applied Psychology, 81 (1): 36-51.

20. Meindl, J. R. 1995. The romance of leadership as follower-centric theory: A social constructionalist approach. Leadership Quarterly, 6 (3): 329-341.

21. Meindl, J. R. 1988. On the romanticized perceptions of charisma. Unpublished manuscript, School of Management, State University of New York at Buffalo.

22. Meindl, J. R. \& Ehrlich, S. B. 1997. The romance of leadership and the evaluation of organizational performance. Academy of Management Journal, 30 (1): 91-109.

23. Meindl, J. R. \& Ehrlich, S. B. \& Dukerich, J. M., 1985. The romance of leadership. Administrative Science Quarterly, 30: 78-102.

24. Meindl, J. R. \& Ehrlich, S. B. 1988. Developing a romance of leadership scale. Proceedings of the Eastern Academy of Management, 133-35. 
25. Micali, P. J. 1981. Success handbook of salespeople. Boston, CPI Publishing Company, Inc.

26. Morgan, G. 1988. Teaching MBAs transformational thinking. In R. E. Quinn \& K. S. Cameron (Eds.), Paradox and transformation: Toward a theory of change in organization and management. Cambridge, MA: Ballinger.

27. Nunnally, J. C. 1978. Psychometric theory. New York: McGraw-Hill.

28. Peters, T. \& Austin, N. 1985. A passion for excellence. New York: Random House.

29. Rosenberg, M. 1979. Conceiving the self. New York: Basic Books, Inc.

30. Waldman, D. A., Bass, B. M. \& Yammarino, F. J. 1989. Adding to leader-follower transactions: The augmenting effect of charismatic leadership. ONR Technical Report No.3. Binghamton, NY: Center for Leadership Studies, State University of New York.

31. Weber. M. 1968. Max Weber on charisma and institution building. Chicago: The University of Chicago Press.

32. Wells, L. E., \& Marwell, G. 1976. Self-esteem: Its conceptualization and measurement. Beverly Hill, CA: Sage Publications.

Notes 